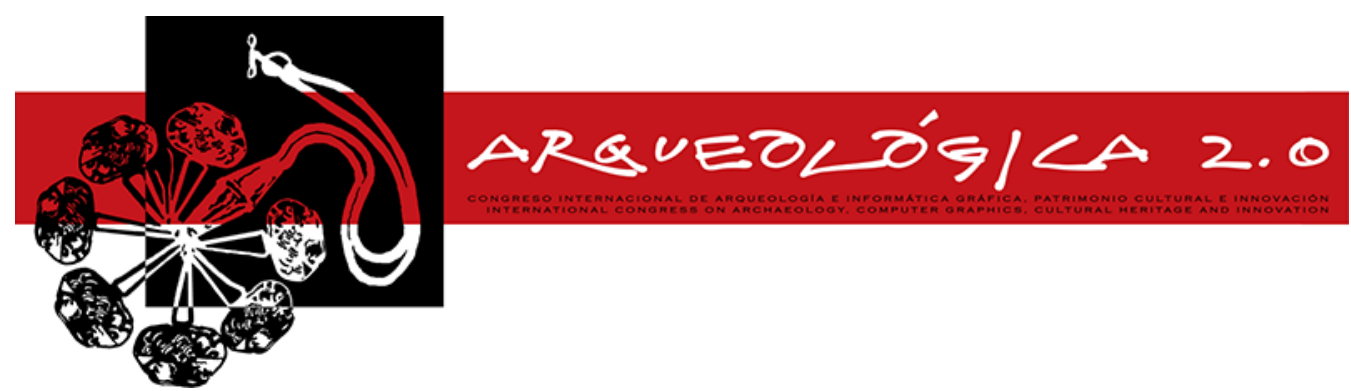

Proceedings of the $8^{\text {th }}$ International Congress on Archaeology, Computer Graphics, Cultural Heritage and Innovation

'ARQUEOLÓGICA 2.0'

in Valencia (Spain), Sept. $5-7,2016$

DOI: $\mathrm{http}: / / \mathrm{dx}$. doi.org/10.4995/arqueologica8.2016.3535

\title{
TRATAMIENTO DE DATOS TLS MEDIANTE EL EMPLEO DE IMÁGENES ESFÉRICAS: APLICACIÓN A LA DOCUMENTACIÓN DE LA SALA CAPITULAR DE LA CATEDRAL DE JAÉN
}

\author{
TLS DATA PROCESSING USING SPHERICAL IMAGES: APPLICATION TO THE CHAPTERHOUSE OF THE \\ CATHEDRAL OF JAEN
}

\author{
José M. Gómez-López , José L. Pérez-García, Carlos Colomo, Javier Cardenal, Emilio Mata
}

Dpto. Ingeniería Cartográfica, Geodésica y Fotogrametría, Escuela Politécnica Superior, Campus Las Lagunillas, Universidad de Jaén, 23071 Jaén, España. jglopez@ujaen.es; ilperez@ujaen.es; cmcj0002@red.ujaen.es; icardena@ujaen.es; emata@ujaen.es

\begin{abstract}
:
Nowadays, one of the techniques more used for documentation of cultural heritage is terrestrial laser scanner (TLS). This kind of instrumental has become essential in this kind of heritage projects. However, in many projects, the captured information by these systems are excessive, which hinders its data processing and information extraction. But when the documentation purpose is limited to the visualization or dissemination, the final products can be simpler than those obtained from the dense point clouds and the resulting detailed models. In this paper it is presented an approach based on TLS data processed with spherical images algorithms. TLS point clouds are used to simulate spherical images allowing the storage, processing, visualization and dissemination of both data and products. This approach has been applied to a real study case in the documentation of the chapterhouse of the Cathedral of Jaén.
\end{abstract}

Key words: spherical images, terrestrial laser scanner, spherical photogrammetry, cultural heritage documentation

Resumen:

En la actualidad, una de las técnicas más utilizadas para la documentación del patrimonio cultural es el escáner láser terrestre, instrumental que se ha convertido en imprescindible en cualquier empresa que se dedique a estos fines. Sin embargo, en muchos casos la información capturada por estos sistemas es excesiva, lo que dificulta su procesado y la posterior extracción de información. Por otro lado, cuando el fin es solo la visualización o la divulgación del monumento, los productos necesarios son más simples que la nube de puntos densa o una modelización de gran precisión obtenida a partir de esta nube. En este trabajo se presenta una filosofía de trabajo con datos TLS basada en el uso de imágenes esféricas obtenidas a partir de las nubes de puntos provenientes del escaneado, que facilita su almacenamiento, procesado, visualización y divulgación. Finalmente se presenta la metodología llevada a cabo y los resultados obtenidos en un caso de estudio real, más concretamente en la documentación de la Sala Capitular de la Catedral de Jaén.

Palabras clave: imágenes esféricas, escáner láser terrestre, fotogrametría esférica, documentación del patrimonio cultural

\section{Introducción}

En todo trabajo de documentación del patrimonio mediante técnicas basadas en escáner láser terrestre, el objetivo principal de la fase inicial de captura, es aprovechar la información capturada de manera masiva, de tal forma, que estos datos no sean insuficientes ni excesivamente redundantes. En definitiva, que estos datos sean lo suficientemente densos para cumplir el propósito para el que son capturados, pero que no se produzca una innecesaria captura de información no útil que pueda suponer un sobrecoste en los tiempos y en el presupuesto destinado al trabajo de documentación planteado.

Este objetivo se plantea porque uno de los principales problemas, cuando se trabaja con esta tecnología, es la alta densidad de información que se obtiene. De hecho, hoy en día resulta más útil y eficaz obtener toda la geometría del entorno de trabajo en la fase de medición, para luego, en oficina, decidir cuál será la información que se extrae o se aprovecha puntualmente. Este hecho implica dos problemas. Por un lado, se generan archivos digitales de gran volumen, teniendo en mayor o menor

`Corresponding Author: José M. Gómez-López, jglopez@ujaen.es 
medida un problema de almacenamiento de información, y por otro lado, un post-proceso de los datos para extraer la información relevante que requiere bastante tiempo y recursos informáticos. Es por esto, que el tratamiento de los datos escáner láser terrestre sea un tema de gran interés en la comunidad científica relacionada con esta área de trabajo.

Por otro lado, son muy numerosos los artículos y trabajos publicados cada año, donde se utiliza esta técnica en combinación con otras técnicas como la fotogrametría aérea (UAV), la fotogrametría de objetos cercanos o la videogrametría, para aplicaciones de reconstrucción, modelado $3 \mathrm{D}$, etc.

La metodología que aquí se plantea, trata de conseguir un enfoque distinto al habitual de tratamiento y aprovechamiento de los datos de escáner láser presente en la mayoría de las aplicaciones informáticas desarrolladas para este fin, para agilizar los procesos de almacenamiento, procesado, extracción de información relevante y la fusión con datos procedentes de otras técnicas o instrumentos.

Para explicar el fundamento de este planteamiento, podríamos apoyarnos en dos definiciones propuestas por Mills y Barber (2003). Por un lado, se define escáner láser terrestre como "un dispositivo fijo en tierra que utiliza un láser para medir las coordenadas tridimensionales de una región determinada de una superficie de un objeto, en un orden sistemático a un velocidad alta en tiempo real". Por otro lado, también se define la nube de puntos como, "una colección de coordenadas $\mathrm{XYZ}$ en un sistema de referencia común que representa al observador, una comprensión de la distribución espacial de un objeto o lugar, que también puede incluir información adicional como la intensidad o el valor RGB". Teniendo en cuenta estas definiciones, se podría deducir que:

- Se dispone de un instrumento que hace medidas puntuales en un orden sistemático.

- El producto que genera, es una estructura sin ningún orden, sin ninguna relación implícita o explícita entre elementos.

- El propósito seria entonces reconstruir ese orden, para obtener un producto con una estructura topológica, que facilite las operaciones. Esto se podría traducir en convertir esa colección de coordenadas, en una estructura de almacenamiento de tipo ráster.

Se puede encontrar numerosa bibliografía del empleo de esta estructura para solventar los problemas de registro o de extracción de elementos. Por ejemplo, en Chen et al. (1998) se propone un método para determinar las tres mejores homologías entre dos imágenes de distancia. El algoritmo line-based planteado por Stamos y Leordean (2003) está basado en la segmentación de las imágenes de distancia y la extracción de segmentos rectos y planos. Por otro lado, Moldovan et al. (2009) utiliza la información de la intensidad y el operador SIFT para obtener puntos comunes. Siguiendo esta línea, Theiler y Schindler (2012) determina puntos comunes a varios escaneados, a partir de la intersección de tres planos encontrados en los escaneados, ya que estos puntos tienen geometría más estable, aplicando el operador RANSAC a la pirámide de imágenes generadas a partir de las imágenes correspondiente a cada escaneado o un ejemplo más curioso de utilización de estas imágenes lo podemos encontrar en Nüchter et al. (2011), que consiste en un método de registro automático de escenas $360^{\circ}$ en ciudades, a partir de la obtención del borde o línea que genera los edificios con el cielo (Skyline) en cada toma e identificar características comunes sobre estas líneas.

\section{Metodología}

El trabajo que se presenta está estructurado en una serie de fases que permiten la definición e implementación de la metodología propuesta:

- Generación de imágenes esféricas a partir de la nube de puntos.

- Registro de la nube de puntos a partir de las imágenes esféricas utilizando modelos fotogramétricos adaptados.

- Extracción de puntos de control a partir de las imágenes esféricas para la fusión con imágenes procedentes de cámaras fotográficas y proceso de orientación fotogramétrica.

- Aplicación de la metodología en un caso de estudio real, validación y generación de productos asociados.

\section{Generación de las Imágenes esféricas}

Como se definió en el apartado anterior, el escáner láser terrestre realiza una medición en un orden sistemático, esto se traduce en un barrido horizontal y vertical del objeto, midiendo la distancia respecto a éste en cada punto, es decir, las observaciones que realiza este instrumento están basadas en un sistema esférico (Fig. 1).

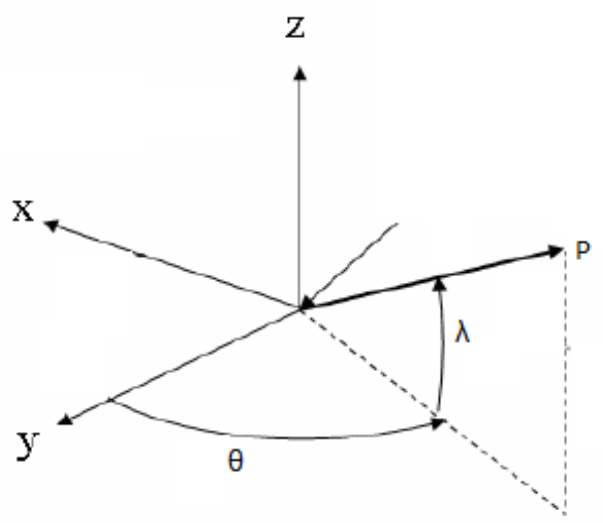

Figura 1: Sistema Cartesiano y Esférico

El primer paso para la generación de las imágenes, sería transformar las coordenadas $X Y Z$ obtenidas, en coordenadas esféricas $\theta, \lambda, D$, Eq. (1):

$$
\theta=\operatorname{atg}\left(\frac{y}{x}\right) ; \lambda=\operatorname{acos}\left(\frac{z}{D}\right) ; D=\sqrt{x^{2}+y^{2}+z^{2}}
$$


A partir de aquí, se obtiene la estructura ráster. En primer lugar se calculan los extremos de los ángulos ( $\theta$ min, $\lambda$ max, $\theta \max , \lambda \min )$, definiendo así la superficie esférica que se ha escaneado, y posteriormente una vez calculado el paso angular o resolución del escáner utilizada a partir de los datos, se añadirán a dicha estructura ráster los puntos capturados en dicho escaneo.

Por último, queda elegir las ecuaciones proyectivas que permitan pasar de la esfera a la proyección y definir el tamaño de la imagen resultante. En Houshiar et al. (2015) se hace un estudio de las proyecciones para mejorar la extracción de elementos y descriptores, para posteriormente hacer un registro automático. En este trabajo se ha elegido por defecto la proyección equirectangular o de Plate Carrée.

Esta proyección tiene una pequeña desventaja, como es la deformación que se produce a partir de latitudes por encima de $80^{\circ}$, lo que hace que se dificulte la visualización de datos que se encuentran en estas zonas. Para solucionar esto, se ha recurrido a otras proyecciones, de tipo gnomónica para la visualización de estos datos (Fig. 2).

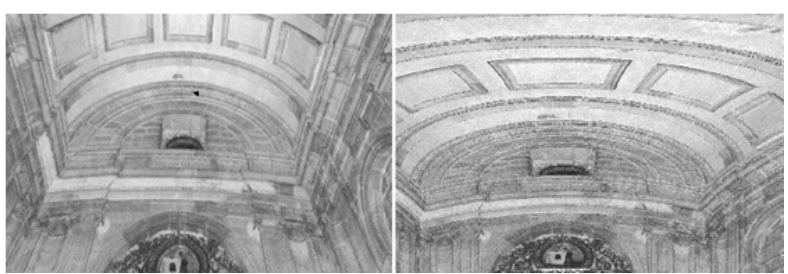

Figura 2: Izquierda: proyección Gnomónica. Derecha: proyección Equirectangular

Según lo comentado anteriormente, el tamaño de la imagen queda definido por, Eq. (2):

$$
\mathrm{f}=\frac{\lambda_{\max }-\lambda_{\min }}{\delta \alpha} ; \mathrm{c}=\frac{\theta_{\max }-\theta_{\min }}{\delta \alpha}
$$

donde:

$$
\begin{aligned}
& \text { - } \quad f y c \text { son el número de filas y de columnas } \\
& \text { - } \quad \delta \alpha \text { es la resolución espacial. }
\end{aligned}
$$

Para completar la conversión entre estructuras de almacenamiento, quedaría asignar a cada celda, o pixel de la imagen, el valor de la distancia con respecto al origen del escáner. Así, cada posición de la imagen define dos ángulos, horizontal y vertical, y el valor de esa celda tiene almacenada la distancia del punto o los puntos que se encuentren dentro de esta.

En este momento surge el primer inconveniente de esta conversión, como es la interpolación, o la conversión de entidades puntuales en entidades zonales, y como eso puede afectar a la posterior recuperación de la estructura inicial de nube de puntos. Dado que la nube de puntos no es una estructura regular con densidad y espaciado angular constante y el ráster si lo es, dado que tiene tamaño de celda fijo y sólo almacena un dato por celda, habrá que tener en cuenta algunas consideraciones. En primer lugar, existirán celdas donde aparecerán varios puntos y habrá que seleccionar que valor representará al de la celda correspondiente. En este sentido, se puede optar, en función de la aplicación o las necesidades planteadas, por seleccionar el punto más cercano al escáner, el último, el más centrado, o el promedio de todos. Por otro lado, los puntos encerrados en cada celda no tienen por qué encontrarse en el centro de la misma, posición que representa a dicha celda, por lo tanto si se desea recuperar la posición real de los datos habrá que almacenar el offset del punto respecto al centro de la celda (Fig. 3). Este offset es guardado en la misma estructura de almacenamiento.

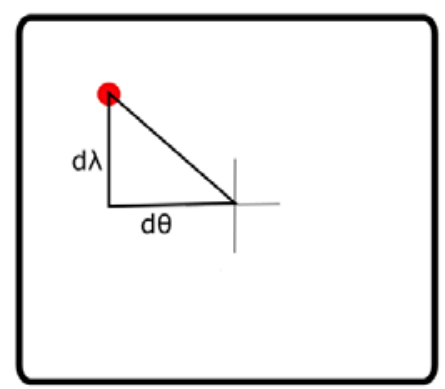

Figura 3: Offset del punto respecto al centro de la celda

Otro aspecto a tener en cuenta en la generación de la estructura ráster, es que en la mayoría de las ocasiones, se va a disponer de información adicional a la distancia de cada uno de los puntos como es la intensidad o el color. En este sentido, el almacenado de esta información se llevará a cabo en la misma estructura creada para la distancia, bien como una capa más o bien como imágenes independientes.

Una vez creada la estructura ráster que representa a la nube de puntos, habría que analizar algunas de las ventajas que esta aporta sobre la estructura original de $X Y Z$. Por un lado, se facilitan todas las operaciones de almacenamiento y recuperación de la información, así como todas las operaciones basadas en la vecindad de los puntos. Por otro lado, esta estructura va a permitir el uso sobre los datos de algoritmos de procesamiento digital de imágenes para generar nuevas imágenes derivadas de distinta información, útiles para la extracción de elementos o características de forma automática.

Por último, se podría también destacar una ventaja evidente respecto al almacenamiento de la información en disco, ya que la conversión entre estructuras significa reducir considerablemente el tamaño de los archivos originales. Por ejemplo, un archivo ASCII de 4 millones de puntos $X Y Z$ tiene un tamaño en disco de alrededor de $200 \mathrm{MB}$, sin embargo, almacenado en imagen esférica en formato TIFF, el tamaño es de $\sim 14 \mathrm{MB}$. En Houshiar y Nuchter (2015), aplican los metodos convencionales de comprensión de imágenes, a las imágenes panorámicas de distancias, color e intensidad para reducir el espacio de almacenamiento, asi como para estudiar los efectos que producen en los datos.

\section{Registro u orientación de las nubes de puntos a partir de modelos fotogramétricos adaptados}

Una de las ventajas de la utilización de las imágenes esféricas, es la fácil adaptación de los modelos propios de orientación fotogramétrica a los datos procedentes de escáner láser terrestre.

En este caso, se implementa un modelo matemático basado en la condición de colinealidad. Por tanto, el 
vector de posición en la esfera $(r)$ y su correspondiente en el sistema de referencia $(R)$ deberán estar alineados en el espacio (Fig. 4). Para ello, habrá que rotar el sistema esférico, y ajustarlo en escala si fuese necesario.

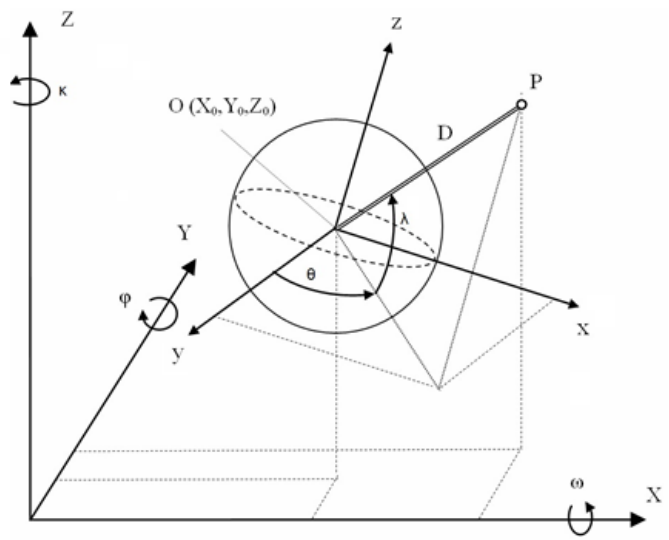

Figura 4: Esquema del modelo de colinealidad adaptado para esféricas

Las matrices que definen esta condición quedarán de la siguiente manera, Eqs. (3, 4, 5 y 6):

$$
\begin{gathered}
\vec{r}=\left[\begin{array}{c}
D \operatorname{sen}(\theta) \cos (\lambda) \\
D \cos (\theta) \cos (\lambda) \\
D \operatorname{sen}(\lambda)
\end{array}\right] ; \vec{R}=\left[\begin{array}{c}
X_{p}-X_{0} \\
Y_{p}-Y_{0} \\
Z_{p}-Z_{0}
\end{array}\right] \\
{\left[\begin{array}{c}
D \cos (\theta) \operatorname{sen}(\lambda) \\
D \cos (\theta) \cos (\lambda) \\
D \operatorname{sen}(\lambda)
\end{array}\right]=K[M(\omega, \varphi, \mathrm{\xi})]\left[\begin{array}{c}
X_{p}-X_{0} \\
Y_{p}-Y_{0} \\
Z_{p}-Z_{0}
\end{array}\right]}
\end{gathered}
$$

Analíticamente seria:

$$
\begin{aligned}
& x S=\frac{\operatorname{sen}(\theta) \cos (\lambda)}{\operatorname{sen}(\lambda)}=\frac{m_{11}\left(X_{P}-X_{0}\right)+m_{12}\left(Y_{P}-Y_{0}\right)+m_{13}\left(Z_{P}-Z_{0}\right)}{m_{31}\left(X_{P}-X_{0}\right)+m_{32}\left(Y_{P}-Y_{0}\right)+m_{33}\left(Z_{P}-Z_{0}\right)} \\
& y S=\frac{\cos (\theta) \cos (\lambda)}{\operatorname{sen}(\lambda)}=\frac{m_{21}\left(X_{P}-X_{0}\right)+m_{22}\left(Y_{P}-Y_{0}\right)+m_{23}\left(Z_{P}-Z_{0}\right)}{m_{31}\left(X_{P}-X_{0}\right)+m_{32}\left(Y_{P}-Y_{0}\right)+m_{33}\left(Z_{P}-Z_{0}\right)}
\end{aligned}
$$

donde:

$$
\begin{aligned}
& \text { - } \quad x s, y s \text { son las fotocoordenadas esféricas. } \\
& \text { - } \quad \theta, \lambda \text { coordenadas esféricas } \\
& \text { - } \quad \mathrm{m}_{\mathrm{nn}} \text { los elementos de la matriz de rotación. }
\end{aligned}
$$

Las incógnitas a resolver son parámetros de orientación externa $(X O, Y O, Z O, \omega, \varphi, \varkappa)$. Este modelo linealizado, será utilizado como una ecuación de observación en el modelo de ajustes de haces.

\section{Fusión con otros datos}

Tal y como se comentó con anterioridad, esta estructura ráster facilita la fusión de datos de distinto tipo. En este sentido, el proceso de fusión de datos láser escáner con datos de imágenes fotográficas tomadas con cámaras convencionales, se ha resuelto extrayendo puntos comunes entre ambos conjuntos de puntos, y utilizándolos como puntos de apoyo para la orientación fotogramétrica de las fotografías.

Cuando se trabaja en proyectos de documentación geométrica del patrimonio cultural, con fines de virtualización de la realidad, puede ocurrir que la utilización de targets o puntos artificiales para la materialización de puntos de apoyo, oculte detalles del objeto o la escena a documentar, o que la colocación de los mismos suponga un problema para el propio objeto o por lo inaccesible de este. Es por esto, que en ocasiones se tenga que recurrir a utilizar detalles o puntos característicos de la escena, que sean identificables en el conjunto de observaciones realizadas.

En este sentido, se puede obtener el apoyo fotogramétrico a partir de la nube de puntos, si esta tiene una resolución espacial equiparable a la de las fotografías. La utilización de las imágenes esféricas, en lugar de la nube de puntos, agiliza mucho el proceso de búsqueda de puntos característicos, obteniendo buenos resultados tras el ajuste fotogramétrico (Fig. 5). Facilitando de esta manera la fusión de datos fotogramétricos y de escáner láser terrestre sin la necesidad de la preseñalización de puntos de control ni de la medida de los mismos mediante técnicas topográficas.

\section{Caso de Estudio: Sala Capitular de la Catedral de Jaén}

La sala capitular (Fig. 6), también llamada Capilla de San Pedro de Osma fue construida en 1556 por Andrés de Vandelvira. Es de planta rectangular de medidas muy proporcionadas, de $14 \mathrm{~m}$ por $7 \mathrm{~m}$, y está adornada por pilastras jónicas, veinticuatro nichos y tres grandes ventanales orientados al oeste. Al frente hay un retablo del siglo XVI de Pedro Machuca, discípulo de Miguel Ángel, siendo la única decoración de la estancia. Está formado por 13 tablas simétricamente distribuidas en torno al motivo central de San Pedro de Osma.

La documentación geométrica se realizó empleando un escáner láser terrestre Leica ScanStation C10, y una cámara réflex Canon EOS D5 MKII. Las características de ambos se especifican en la Tabla 1.

Tabla 1: Características Instrumental

\begin{tabular}{c|c} 
Leica ScanStation C10 & Canon EOS D5 MKII \\
\hline 50,000 puntos $/ \mathrm{seg}$ & $5616 \times 3744$ \\
Alcance hasta $150 \mathrm{~m}$ & $24 \mathrm{~mm}$ y $35 \mathrm{~mm}$ de focal \\
Precisión distancia $6 \mathrm{~mm} / 50 \mathrm{~m}$ & $6.5 \mu \mathrm{m}$ tamaño de pixel \\
Campo de visión $360^{\circ} \times 270^{\circ}$ & \\
Cámara digital $4 \mathrm{Mpx}$ & \\
Compensador doble eje &
\end{tabular}

Para la toma de algunas de las imágenes, se utilizó un mástil telescópico con trípode (Fig. 7).

En total, se realizaron tres escaneos de resolución $1 \mathrm{~cm}$. a $10 \mathrm{~m}$. y 120 imágenes fotográficas con distintas distancias de disparo. 


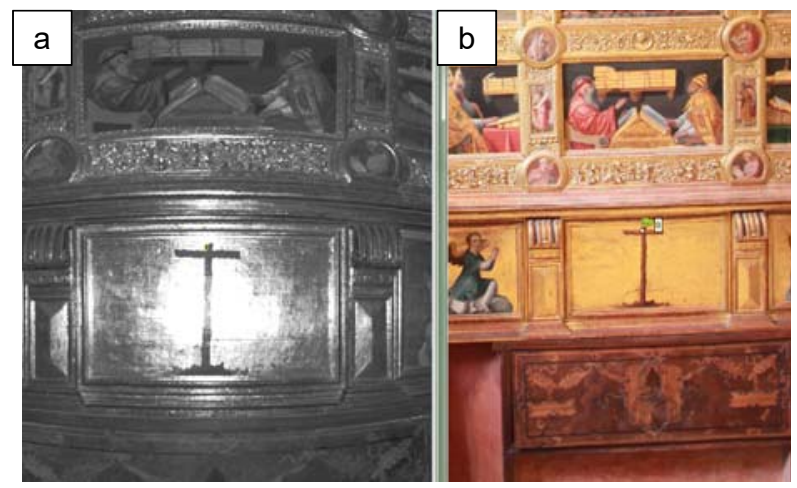

Figura 5: a) Imagen esférica de Intensidades; b) Imagen fotográfica

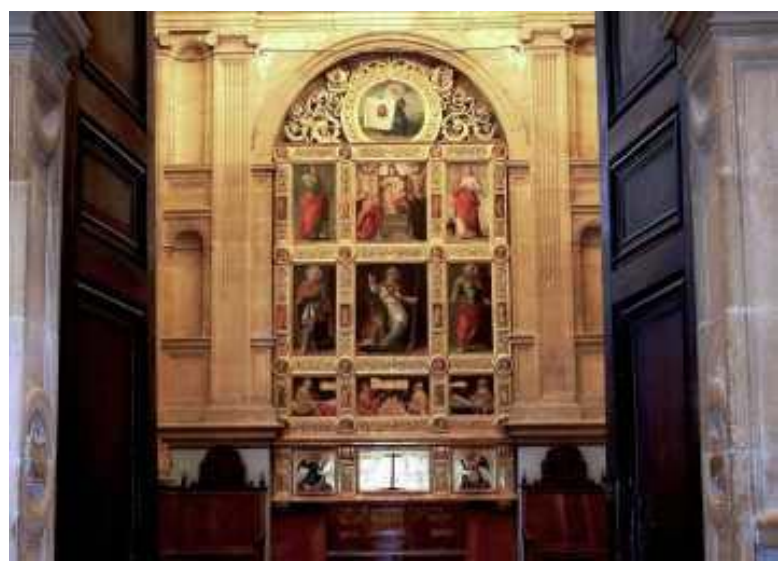

Figura 6: Sala Capitular, Catedral de Jaén

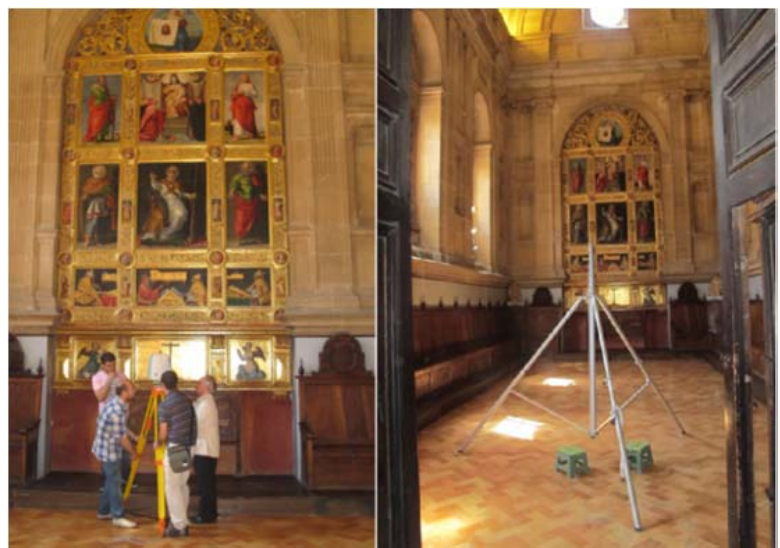

Figura 7: Instrumental empleado

Para aplicar y verificar la metodología propuesta, se implementó una aplicación en Java (Fig. 8) que principalmente permite:

- Abrir/importar nubes de puntos procedentes de escáner láser terrestre.

- Generación, visualización y manipulación de las imágenes esféricas.

- Realización de mediadas manuales y semiautomática de puntos sobre las imágenes.

- Implementación del modelo fotogramétrico propuesto para el cálculo de los parámetros de orientación externa de los escaneos.

- Salida de resultados.

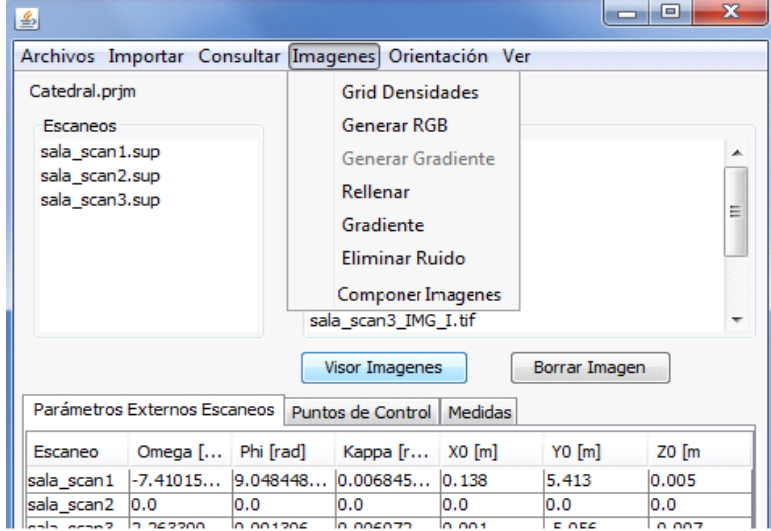

Figura 8: Software LaserScan

Para la orientación de las imágenes se ha utilizado el software Agisoft PhotoScan.

\subsection{Generación de las imágenes y proceso de registro}

En las tres medidas llevadas a cabo con el escáner láser terrestre, se captura a parte de las coordenadas de los puntos, la intensidad y el color como información adicional. De esta forma, se generan 3 imágenes por cada escaneo para guardar la totalidad de la información capturada (Fig. 9).
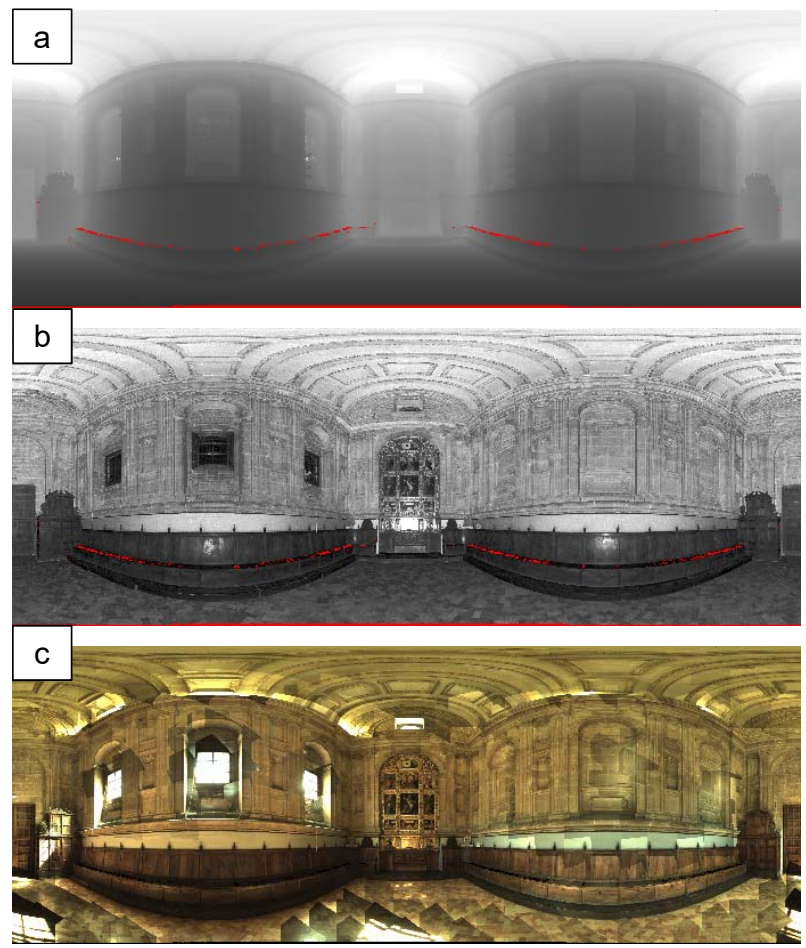

Figura 9: a) distancias; b) intensidad; c) RGB

Una vez generadas estas imágenes, se procede a la orientación de las tres nubes mediante el modelo matemático antes mencionado $y$ de los puntos implicados, obteniendo resultados satisfactorios, con residuos medios en los puntos de control considerados en el ajuste, por debajo de los $5 \mathrm{~mm}$. 


\subsection{Orientación Fotogramétrica}

Para el proceso de orientación fotogramétrica se extraen, a partir de las imágenes esféricas, puntos de control distribuidos por toda la escena de forma manual. Con estos puntos y las imágenes, se procesa todo el bloque mediante el software photoScan, obteniendo como resultado del ajuste, un residuo medio de $6.6 \mathrm{~mm}$ y un error máximo de $7.1 \mathrm{~mm}$ (Fig. 10).

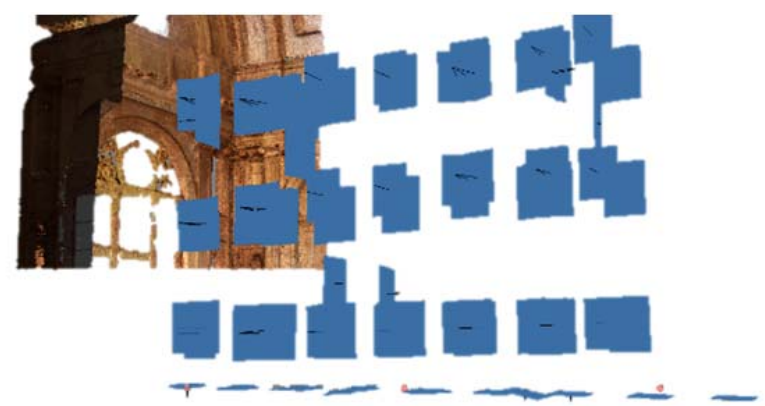

Figura 10: Resultado visual de la orientación de la imágenes y del escáner láser terrestre. Los puntos de color rosado, es la posición de los escaneos

\subsection{Generación de productos}

Los productos que se han generado a partir de los datos obtenidos y procesados son (Fig. 11):

- Nubes de puntos registradas, orientadas o alineadas.

- Modelo 3D foto-realístico a partir la nube y texturizado con las imágenes fotográficas

- Orto-Imágenes considerando diferentes planos.
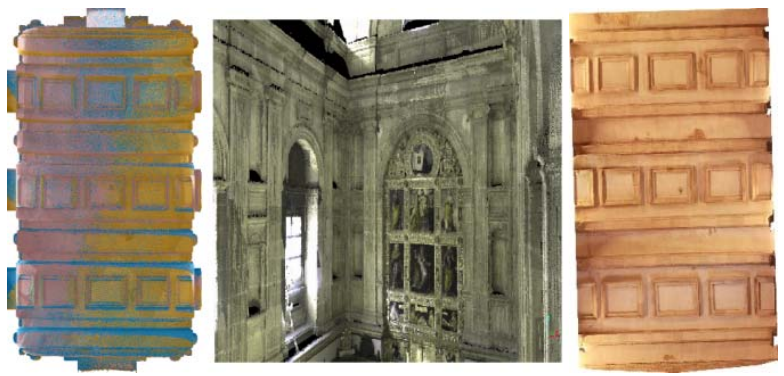

Figura 11: Productos generados

Además se han obtenido otros productos derivados de las propias imágenes esféricas como (Fig. 11):

- Imágenes de inclinación de la normal, donde se pueden apreciar rugosidades con detalle.

- Segmentación de normales en puntos, para extracción de planos específicos para la rectificación de imágenes.

- Extracción de bordes, para la vectorización semiautomática de líneas de ruptura o cambio de dirección de la normal

- Visualización de imágenes esféricas para aplicaciones web utilizando la librería Three.js
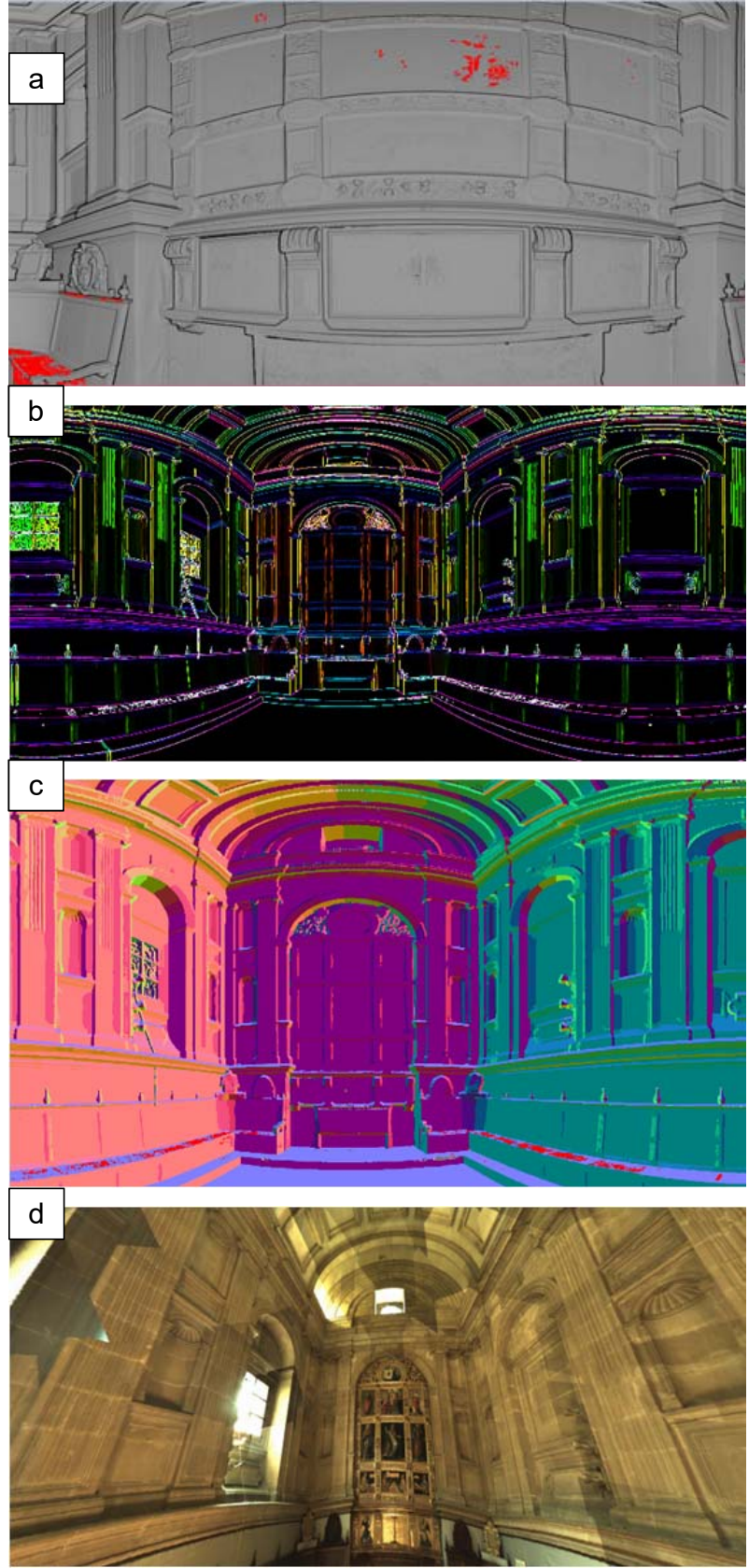

Figura 12: a) Imágenes gradiente; b) imagen extracción líneas; c) imagen segmentación normal; d) imagen RGB

\section{Conclusiones}

Con la metodología de tratamiento de datos TLS propuesta, se consigue el objetivo principal del este trabajo, que era el de obtener el máximo rendimiento a los datos capturados a través de esta técnica. No sólo se mejora la eficiencia en cuanto al almacenamiento y procesamiento de la información, sino que además, la puesta en marcha de esta metodología sobre datos reales, ha sido desencadenante de nuevos planteamientos y productos para la difusión y la documentación de patrimonio histórico cultural.

\section{Agradecimientos}

Agradecimientos al departamento Ingeniería Cartográfica, Geodésica y Fotogrametría y al Grupo de 
Investigación Sistemas Fotogramétricos y Topométricos, por facilitar el material para la realización del presente trabajo.

\section{Referencias}

CHEN, CHU-SONG, HUNG, YI-PING, CHENG y JEN-BO, 1998. A fast automatic method for registration of partiallyoverlapping range images. En Computer Vision, 1998. Sixth International Conference on. IEEE, 1998, pp. $242-248$. DOI: 10.1109/ICCV.1998.710725

HOUSHIAR, H., ELSEBERG, J., BORRMANN, D. y NÜCHTER, A., 2015. A study of projections for key point based registration of panoramic terrestrial 3D laser scan. Geo-spatial Information Science, 18(1), pp. 11-31. DOI: $10.1080 / 10095020.2015 .1017913$

HOUSHIAR, H. y NUCHTER, A., 2015. 3D point cloud compression using conventional image compression for efficient data transmission. En Information, Communication and Automation Technologies (ICAT), 2015 XXV International Conference on. IEEE, 2015. pp. 1-8. DOI: 10.1109/ICAT.2015.7340499

MILLS, J. y BARBER, D., 2003. An Addendum to the Metric Survey Specifications for English Heritage-the collection and archiving of point cloud data obtained by terrestrial laser scanning or other methods. Version 11/12/2003. Available: http://archive.cyark.org/temp/EH3DHeritageaddendum2006.pdf.

MOLDOVAN, D., YANO, S. y INOUE, N., 2009. Automatic registration of multiple range views based on feature matching and feature-depth correspondences. In Intelligent Computer Communication and Processing, 2009. IEEE 5th International Conference on. IEEE, 2009, pp. 169-172. DOI: 10.1109/ICCP.2009.5284767

NÜCHTER, A., GUTEV, S., BORRMANN, D. y ELSEBERG, J., 2011. Skyline-based registration of 3D laser scans. Geospatial Information Science, 14(2), pp. 85-90. DOI: 10.1007/s11806-011-0449-4

STAMOS, I. y LEORDEAN, M., 2003. Automated feature-based range registration of urban scenes of large scale. En Computer Vision and Pattern Recognition, 2003. Proceedings. 2003 IEEE Computer Society Conference on. IEEE, 2003 vol. 2, pp.555-561. DOI: 10.1109/CVPR.2003.1211516

THEILER, P. W. y SCHINDLER, K., 2012. Automatic registration of terrestrial laser scanner point clouds using natural planar surfaces. ISPRS Annals of Photogrammetry, Remote Sensing and Spatial Information Sciences, 2012, vol. 3, pp. 173-178. 